10 years ESJ

Special edition

\title{
Biomedical Research Regulation Challenges in Countries in Transition: Georgian Experience
}

\author{
Karen Mulkijanyan, PhD \\ Tbilisi State Medical University I. Kutateladze Institute of \\ Pharmacochemistry; Georgian Association for Laboratory Animal Science \\ (GALAS), Georgia \\ Levani Chitiashvili, DVM \\ National Center for Disease Control and Public Health (NCDC); \\ Georgian Association for Laboratory Animal Science (GALAS), Georgia \\ Marine Ramishvili, PhD \\ National Center for Disease Control and Public Health (NCDC); \\ Georgian Association for Laboratory Animal Science (GALAS), Georgia \\ Nino Megrelishvili, MD, PhD, Professor \\ David Aghmashenebeli University of Georgia (DAUG), Tbilisi, Georgia
}

Doi: $10.19044 /$ esj.2021.v17n18p41

Submitted: 02 November 2020

Accepted: 19 January 2021

Published: 01 June 2021
Copyright 2021 Author(s)

Under Creative Commons BY-NC-ND

4.0 OPEN ACCESS

Cite As:

Mulkijanyan K., Chitiashvili L., Ramishvili M. \& Megrelishvili N. (2021). Biomedical Research Regulation Challenges in Countries in Transition: Georgian Experience. European Scientific Journal, ESJ, 17(18), 41. https://doi.org/10.19044/esj.2021.v17n18p41

\section{Abstract}

Regulation of biomedical research is a complex task, including ethical aspects subdivided into issues related to research on humans and laboratory animals. Involvement of human subjects is under the strict guidance of relevant regulatory documents common to most countries. Regarding animals, these aspects may vary significantly in nations with different socio political and economic factors of transition. From the other side, contemporary biomedical research suggests, amongst other, close collaboration of scientific and educational institutions from different countries. In Georgia-like countries in transition, this process requires significant amendments to the legislation of biomedical research, as international state-of-the-art regulations require, on one hand, compliance with proper guidelines for use of laboratory animals 
involved in the research process, and on the other - relevant vivarium infrastructure and qualified staff. The current study aimed to collect opinions and experiences from the corresponding Georgian institutions and identify and propose step-by-step solutions to overcome existing challenges. To achieve the goal, we compiled a questionnaire about the management, conduction, and monitoring of biomedical research and sent it to relevant organizations. Questions concerning an institutional policy on the use of laboratory animals, staff qualifications, and infrastructure of units for animal housing/breeding (vivariums or similar), were included as well. The survey revealed the major gaps, among which yet absent national legislative framework appeared of greatest importance, as it allows most institutions' authorities not to perceive the need to adopt accepted standards at their level. This leads to a decreased credibility of the research, and forces scientists to use international regulations that are quite challenging because of the current state of scientific infrastructure in countries in transition. To overcome the identified problems, we have proposed several solutions, such as a universal package of institutional regulations and a draft amendment to the existing legislation to form a national policy on animal welfare.

Keywords: Biomedical research, legislation, laboratory animals, GALAS

\section{Introduction}

At the present stage of development of biomedical science, its clinical and theoretical sections cannot develop without experimental research. So, at a certain stage of research (so called phase I and II of clinical trials), it is common practice to assess the properties and effectiveness of a new drug, vaccine and/or medical device, the result of which cannot be reliably predicted on a person, through experimental testing, in other words, deliberately subject a person even a group of people to unknown, possibly dangerous influences. As this is contrary to Article 3 ("Prohibition of torture") and Article 5 ("Right to liberty and security") of the European Convention on Human Rights, which suggests that no one can be subject to medical, scientific or other experiments without voluntary consent, the researchers are obliged to initially conduct experiments on laboratory animals to minimize the risk of harmful effects on the human body.

The issue remains relevant, despite the development of information technology and the constant expansion of the capabilities of artificial intelligence, an increase in the number of software products aimed at simulating certain biological processes by means of mathematical algorithms (Mager et al., 2001; van der Graaf et al., 2016; Jean-Quartier et al., 2018; Cortesi et al., 2020). The main problem of creating such systems is a large number of interrelated processes occurring in a macroorganism, the variability 
of changes and the mutual influence of which is still quite difficult to algorithmize (e.g., blood rheology, the effect of drugs on the body as a whole, etc.) due to insufficient factual knowledge about them (Gawrylewski, 2007; Fisher et al., 2018; Fabian et al., 2019). Considering the above, a researcher is forced to turn for a kind of "help" to laboratory animals.

In turn, the use of animals in biomedical research is one of the most important international ethical issues of contemporary science and the question of the human attitude towards animals has often been raised. Nowadays in science there are two conflicting key imperatives: freedom of scientific research on one hand, on the other, the need to restrict this freedom in the interests of man (Rogozea et al., 2014; Guidotti, 2017). Moreover, the rapid progress in the creation of products and technologies, and on the other hand, the lack of tools for resolving bioethical conflict causes disproportions and contradictions when using animals in experiments. Taking this into account, the only mechanism for their resolution is the application of regulatory measures - a task that should be set by state structures, public institutions, and professional associations.

Currently, the basic principles of working with laboratory animals are "Directive 2010/63/EU of the European Parliament and of the Council of the European Union of 22 September 2010 on the protection of animals used for scientific purposes" and the "Guide for the Care and Use of Laboratory Animals" in which only in relation to ethical standards, the requirements for the very procedure for the ethical examination of conducted research, methods of euthanasia, requirements for the special education of personnel are described in detail and strictly regulated, the procedures are classified according to the degree of severity depending on the level of the perceived pain and suffering inflicted on the animal during the procedure. These standards are mandatory for scientists of the USA and all countries of European Union, however, in Georgia-like countries in transition they often do not have the force of the law.

Nevertheless, the influence of international standards on the work of local researchers is realized through the requirements of the vast majority of scientific journals to comply with the rules set out in aforesaid regulations. Due to the fact that, when performing scientific research, scientists are obliged to publish the results obtained in peer-reviewed journals, the requirements of the above Directive and Guide actually become mandatory.

\section{Methods}

The Georgian Association for Laboratory Animal Science (GALAS) compiled and distributed the questionnaire among Georgian universities and research institutions. Existing structural units that use laboratory animals for educational purposes, fundamental or applied research served as a criterion to 
include in the survey. The questionnaire comprised several modules related to institutional policy on animal welfare, conduction, monitoring of biomedical studies, and the state of the infrastructural units (vivariums, labs, etc.), and qualification of the personnel. After the analysis of results and consultations with international experts, we have drafted a regulations package both for research and governmental entities.

\section{Results}

Analysis of the questionnaire revealed major gaps: i) each research institution was operating on their own considerations, ii) no state policy on use and care of laboratory animals existed; iii) scientists are forced to be temporarily guided by international regulations that sometimes is very challenging; iv) the absence of legislative basis along with mostly amortized animal facilities and equipment has negative impact on participation in international scientific projects, obtaining funding for the research, as well as publishing in peer reviewed journals, due to non-compliance with internationally accepted standards and hence lack of credibility of results; v) an absence of registration or licensing requirements makes it a challenge to definitively identify all the institutes that are currently using animals in this country.

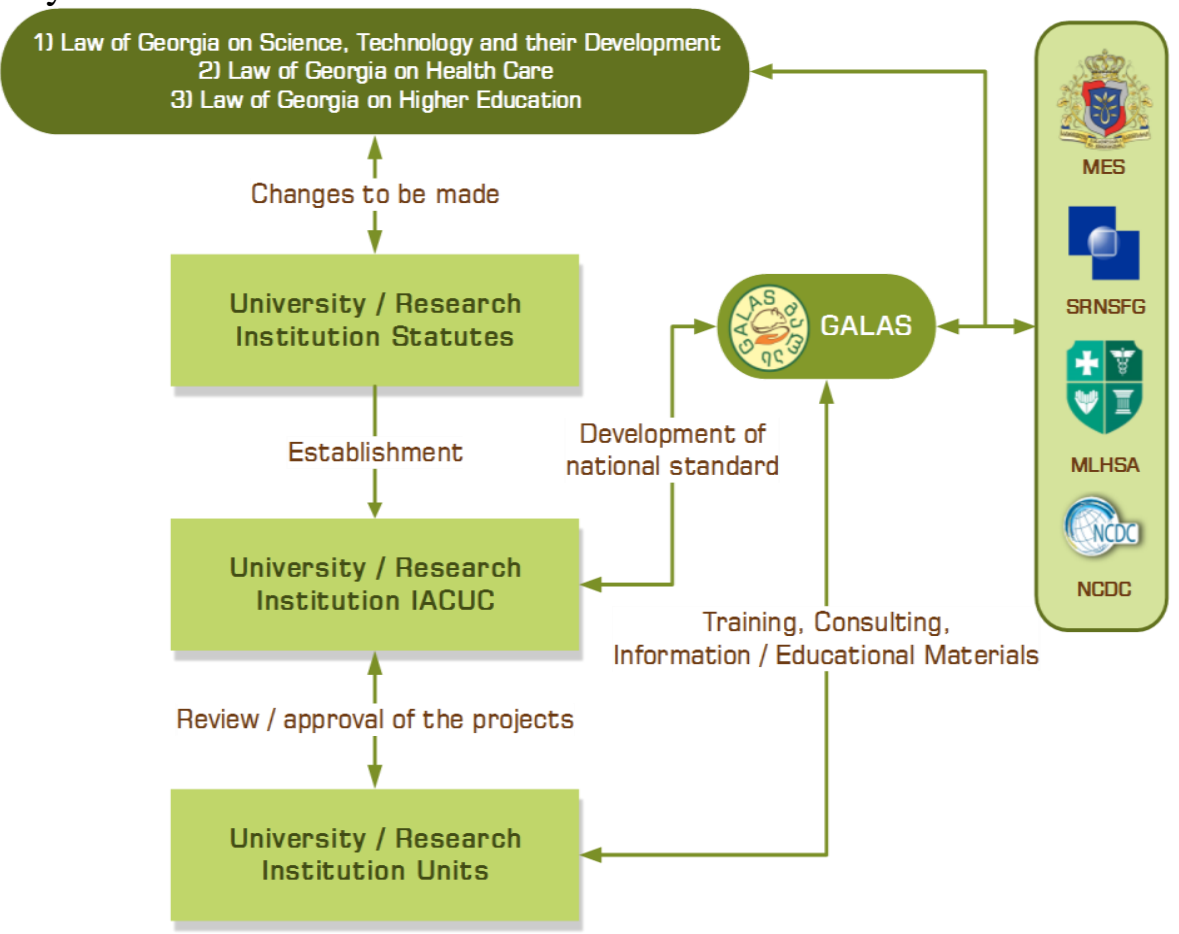

Figure 1. Suggested Legislative System for Animal Care and Use 
NCDC - National Center for Disease Control and Public Health of Georgia; MLHSA - Ministry of Internally Displaced Persons from Occupied Territories, Labor, Health and Social Affairs of Georgia; SRSNSFG - Shota Rustaveli National Science Foundation of Georgia; MES - Ministry of Education, Science, Culture and Sport of Georgia; IACUC - Institutional Animal Care and Use Committee; GALAS - Georgian Association for Laboratory Animal Science.

Considering various opinions about adaptation and implementation of international standards for biomedical research in Georgia and based on objective reality, on the first stage the Inter Institutional Animal Care and Use Committee at National Center for Disease Control and Public Health of Georgia (NCDC) has been established that now allows researchers to conduct and monitor all studies in accordance with international animal biosafety level (ABSL-2/ABSL-3) standards. Memorandums of Collaboration were signed between GALAS and major Georgian biomedical institutions, including the National Center for Disease Control and Prevention, Center for Experimental Biomedicine, Laboratory of Ministry of Agriculture, and Tbilisi State University. The above-mentioned institutions were provided with a unified set of regulatory documents regarding contemporary ethical standards and regulations in animal housing, nutrition and routine operations. In addition, several workshops were held for institutional personnel to increase their competence in ethical issues, and a draft of appropriate amendments to Georgian legislation is ready for submission to the Parliamentary Committee on Science and Education (Fig. 1).

\section{Conclusion}

Establishment and implementation of Georgian standards for the care and use of research animals harmonized with those of the international biomedical research community will raise the quality and credibility of biomedical research in Georgia and facilitate the involvement of the Georgian scientific projects in international collaboration.

The ratification of the European Convention for the Protection of Vertebrate Animals used for experimental and other scientific purposes, along with the phased implementation of the fundamental provisions of EU Directive 2010/63/, remain among the primary objectives for further success and recognition of Georgian biomedical science.

To our knowledge, the presented work is the first study ever carried out in the countries of the former Soviet Union. Considering the fact that the problems raised in the work are common to these states, the authors suggest that proposed approach may be useful for optimizing biomedical research in Georgia-like countries in transition. 


\section{Disclaimer}

The opinions and views expressed herein belong to the authors and do not reflect an official position of any other organization.

\section{References:}

1. Cortesi, M., Liverani, C., Mercatali, L., Ibrahim, T., \& Giordano, E. (2020). An in-silico study of cancer cell survival and spatial distribution within a 3D microenvironment. Sci Rep 10, 12976. https://doi.org/10.1038/s41598-020-69862-7

2. Directive 2010/63 / EU of the European Parliament and of the Council of the European Union of 22 September 2010 on the protection of animals used for scientific purposes. (2010). Official Journal of the European Union L276, 53, 33-80.

3. European Convention on Human Rights. https://www.echr.coe.int/Documents/Convention_ENG.pdf

4. Fabian, E., Gomes, C., Birk, B., Williford,T., Hernandez, Tz.R., Haase, Ch., Zbranek, R., van Ravenzwaay, B., \& Landsiedel, R. (2019). In vitro-to-in vivo extrapolation (IVIVE) by PBTK modeling for animal-free risk assessment approaches of potential endocrinedisrupting compounds. Arch Toxicol 93, 401-416. https://doi.org/10.1007/s00204-018-2372-z

5. Fisher, C., Hatley, O., van Vugt, B., Bois, F., Escher, S., \& Gardner, I. (2018). In vitro to in vivo extrapolation of valproic acid hepatotoxicity: A biokinetic and physiologically based toxicokinetic informed approach. Toxicology Letters. 295. S246. https://doi.org/10.1016/j.toxlet.2018.06.1015

6. Guide for the care and use of laboratory animals. $8^{\text {th }} \mathrm{ed}$. (2011).The National Academies Press.

7. Guidotti, T.L. (2017). Scientific Freedom and Human Rights, Archives of Environmental \& Occupational Health, http://doi.org/10.1080/19338244.2017.1364522

8. Jean-Quartier, C., Jeanquartier, F., Jurisica, I., \& Holzinger, A. (2018). In silico cancer research towards 3R. BMC Cancer. https://doi.org/10.1186/s12885-018-4302-0

9. Mager, D.E. \& Jusko, W. (2001). General pharmacokinetic model for drugs exhibiting target-mediated drug disposition. J. Pharmacokinet. Pharmacodyn., 28, 507-532; https://doi.org/10.1023/A:1014414520282

10. Rogozea,L., Purcaru,D., Leasu F., \& Nemet,C. (2014). Biomedical research - opportunities and ethical challenges. Romanian Journal of Morphology \& Embryology, 55 (suppl 2), 719-722. 
11. van der Graaf, P.H., Benson, N., \& Peletier, L.A. (2016). Topics in Mathematical Pharmacology. J Dyn Diff Equat 28, 1337-1356. https://doi.org/10.1007/s10884-015-9468-4 